\title{
Trends of Students of the College of Basic Science towards Teaching the Course of Athletics and Health by Using Computer Technology in the World Islamic Sciences and Education University (WISE)
}

\author{
Ibrahim Abdul Ghani Salameh ${ }^{1} \&$ Mohammad Falah Ali Khawaldeh ${ }^{2}$ \\ ${ }^{1}$ College of Physical Education and Sport Science, The Hashemite University, Jordan \\ ${ }^{2}$ Faculty of Educational Sciences, World Islamic Sciences \& Education University, Jordan \\ Correspondence: Ibrahim Abdul Ghani Salameh, College of Physical Education and Sport Science, The \\ Hashemite University, Jordan. Tel: 962-798-985-303. E-mail: m.khawaldeh64@yahoo.com
}

\author{
Received: May 12, 2014 Accepted: August 18, 2014 Online Published: October 29, 2014 \\ doi:10.5539/ies.v7n11p147 URL: http://dx.doi.org/10.5539/ies.v7n11p147
}

\begin{abstract}
The Study aimed at identifying the trends of the students of basic sciences College in the World Islamic Sciences and Education University towards teaching health and sport course by using computer technology as a teaching method, and to identify also the impact of the variables of academic level and the gender on the students' trends. The study sample was selected among 140 male and female students (65 males and 75 females) from Basic Science College in The World Islamic Sciences and Education University in order to test the hypotheses of the study, a questionnaire was made to suite the nature of study objectives to identify the students' attitudes towards using computer in teaching health and sport course. Wherein statistical processors were used: (SMA, standard deviation, (T-Test) and results of the analysis were as follows: There are positive attitudes towards teaching health and sport course by using computer technology as a teaching method, as well as the computing experience has a statistically significant impact on the students' attitudes towards using computer. Also the lack of statistically significant differences in the male and female students' trends towards using computer technology attributed to the academic level as a teaching method.
\end{abstract}

Keywords: trends, course of athletics and health, computer technology

\section{Introduction and Significance}

Scientific development and technology are considered a basic part in the life of humans, for scientific technologies and modern educational means assisted on improving and developing learning and educational operation. It became with a clear effect on the teaching and educational process. This technology significance became bigger after the advent of the (Internet services, World Wide Web-WWW), (Digital library), (Interactive TV), Electronic Learning), (Video Conferences), (Virtual Library and Museums). Therefore, these tools and apparatuses are considered a basic part for the academicians and students; they motivate them for positive participation and getting knowledge and communication with others at different parts of life.

The computer apparatuses and the Internet entered the fields of education and scientific research to enrich the educational process at its different levels, and it is not possible to escort development and change in this life too far. The developed countries did many changes and modifications on the content of its educational methods, styles of teaching, and means and activities of educational technology and on preparing instructors to escort development and scientific progress, and this change added to the instructors and learner roles and new responsibilities were unavailable before. The learner became an active researcher seeking adaptation, coexisting and interacting with occurring developments at the field of technology and communications, and it is effective element in developing himself and his community. But the instructor, his role became a designer of the educational environment, and works activity on using the modern educational styles which share in developing his students' abilities, higher thinking skills and skills of solving problems and decision-making through the Internet.

And due to what the computer is characterized with traits and characteristics distinguished it from other educational means, it entered as a computer assisted instruction-CAI at a great number of the world states and at an extensive haste, and the most important of these traits are: 
- Variety in showing styles of information to the learner, the thing that takes him far away from feeling with boredom.

- Easiness in getting and reaching to information from all over the world, and check up opinions and points of view of scholars, researchers and specialists at all fields.

- Organizing both operations of thinking and learning at the learner, and the learner actual joining in the educational operation, that made him positive and towards learning.

- Introducing arousing desire, various educational Programs, which fit propensities and learners' needs from a part and observing the individual differences among them from the other, that makes them more incentive and motivating to learning.

- Making the student feel that he is escorting the technical and technological programs.

- Increase opportunities of self-learning and offer immediate and direct feed-back to the learner after each response, without the learner's feeling tight as a result of the repeated wrong response.

- Introducing arousing desire and various educational programs.

The significance of this study conceals in reconnoitering the trends of students towards the course of athletics and health by using the College of Basic Science in The World Islamic Sciences \& Education University (wise), the thing that allows foretelling the behavior which will be done by the learner during the learning operation, for directing towards a certain subject affects in the extent of accepting the concepts and the extent of employing it (Subhel \& Ajlouni, 2003).

The study also seeks saving a capacity of basic information, beneficial to the concerned people of using the computer and the Internet in educating athletics and health, and reconnoitering trends of learners due to difference of sex variable.

\section{Trends Measurement}

Measurement of trends of answers introduced by the person about statements organized punctually and scientifically at a scale yielded to certain scientific procedures before being considered a trustworthy scale. And the statement many take a formulation of a question and may be pin-pointing descriptive. And the statements in the scale discuss all sides and related details with subject of the trends and what is possible to appear from patterns in behavior expressing that trend. And the scale organizes an organization that allows putting a single mark or writing a word in front of each statement pin-points the extent of applying that statement on its state, through the extent is put in degrees of intense agreement positively and negatively: I intensely agree greatly, until I disagree of all. Also the scale does organize on organization that allows to transfer answers of the person into a language of how much.

The basic idea in the scale is that the person presents a report about himself when he says that he agrees intensely on that thing, and the scale covers in its statements an appropriate comprehensiveness, a good sample from patterns of behavior by which appears the direction and expresses it.

And when the trends were abundant at persons, and their subject were different, the scale of these trends needs a great number of scales each one is prepared to a certain trend. And stating from variety of communities and differences among them in the cultural pattern, and scientific studies and variety of methods in counting the results in the scales and in formulation of their statements, there is a great variety in the available of the scale in the world at one trend.

\section{Problem of Study and Its Objective}

Trends are considered significant in reconnoitering the extent pliability and wish of learner in participating in the educational operation and what accompanies it of experience, to give a strong indicator of the operation of evaluating the subject, and the extent of its achievement to its objectives (Abu-Shararah, 1996; Bitter, 1982; Al-jabiri, 1993). Some people view that the trend is a sentimental inclination, or a readiness towards accepting something, or refusing it, and expresses it usually by love or hatred (Qatami, 1998; Al-Qasem et al., 2001), and the positive trends share in wish developing or love at the learner in learning a certain subject and employing what he learnt at different stands of life, meanwhile the negative trends may play a role in abstention of learners from learning a certain subject and may be chair be failure in it (Till, 1991). Therefore, recognizing trends of students towards using computer technology in educating the subject of athletics and health (negatively or positively) has a great importance in instructing the educational operation 80 , this study aim at reconnoitering trends of students of the College of Basic Science towards educating the course of athletics and health by using the technology of the computer a mean of teaching at the difference of sex. 


\subsection{Enquiries of Study}

- What is the extent of trends of students of the College of Basic Sciences towards educating the course of athletics and health by using the technology of computer in the World Islamic Sciences and Education University?

- Are there statistical differences at the level of $(0.05<\alpha)$ in trends of students towards using the computer in educating the course of athletics and health in the College of Basic Science ascribed to variable of sex?

\section{Previous Studies}

Through checking the electronic worldly and local references, there are previous studies in this field, some of them are:

(1) Al-Hayek and Shaheen (2006) did a study aimed at reconnoitering the reality of using the Internet in educating students of the Faculty of Physical Education in the University of Jordan and the University of Holwan (Republic of Arab Egypt), and reconnoitering trends of students towards using the net and handicaps that face them in light of some variables on a sample of students from the Faculty of the Physical Education in the University of Jordan and their number is (154) students (males and females), and from students of the Faculty of physical Education in the University of Holwan and their number is (167) students (males and females). The results cleared that students at the Faculty of the Physical Education in the University of Jordan are more using the Internet in the University and at home, and bigger number of them is using the (e-mail) electric mail, and have trends more positive towards using the net in education, and there are more handicaps hinder using the Internet face students of the University of Holwan.

(2) Al-Hayek and Salameh (2006) they both prepared a study aiming at recognizing the effect of using two styles in teaching swimming at the level of skillful performance at students of the Faculty of Physical Education in the University of Jordan. The sample consisted of (35) students distributed between two groups: the first empirical, was taught the required skills by the Internet, that was through students referring to some before-hand limited sites including still and moveable illustrating pictures for the understudy skills, the second is a disincentive group, was taught the regular program educated at the Faculty of Physical Education in the University of Jordan. The results showed the existence of statistical differences at the level of skillful performance for the internet of individuals of the empirical group in the skills of sliding on the belly, skill of the back swimming, and skill of legs beats on the belly, meanwhile there are no statistical differences between both groups in skills of standing in the deep water, and the skills of jumping in the deep water.

(3) Ashawwa and Al-Hayek (2006) had laid a study aimed at reconnoitering the effect of educating by using the computer at the level of anxiety at students of the Faculty of Physical Education in the University of Jordan. And to make sure of that the sample of study was chosen of (40) students (males and females). Results of statistical analysis resulted in that the method of education by using the computer positively affected in decreasing the level of the computer anxiety. And also statistical of differences did not exist between the male students and the female students at examinations of the computer anxiety. And also the results showed that students with more computer experience, and students with higher attainment, have less level of anxiety.

(4) Al-Mahameed (2007) she made an empirical study aimed at recognizing the effect of computerizing the selected sport movement skills on trends of Ninth Basic Grade students towards using computer in educating the subject of Basket-ball and Volley-ball, and aimed at recognizing the effect of both sex and computer experience variables on trends of students towards using computer in education. On a sample consists of students from the Ninth Basic Grade, their number is (148) students (males and females). And results showed the existence of differences statistically indicative for the interest of the empirical group, which used computer in teaching, and existence of differences statistically indicative among trends of students ascribed to both variables: sex (for the interest of females) and the computer experience (for the interest of students with more experience)

(5) Mohnsen (2001) prepared a study about using an educational computerized program in educating physical education and comparing it with education on the classical way. The researcher deduced that students showed high motivation and clear activity for learning by using computer as an assistant education means in showing the educational subject, and their concentration and interaction were bigger than at using the classical method (without using computer).

(6) Al-Hayek (2004) he had done a study aiming at reconnoitering the effect of using the computer in educating the physical education on students trends in the University of Jordan towards it in light of some variables. The results indicated on the experience of positive differences in trends of students towards the computer, and 
students with the most experience in using computer have more positive trends. And results showed non-existence of differences among males and females, and non- existence of differences in trends of students ascribed to academic attainment.

(7) Al-Hayek and Suha (2006), they prepared a study aiming at recognizing the effect of using the computer in educating some methods of the physical education in the University of Jordan and the Hashemite University on trends of students towards learning by using computer in light of some variables on a sample of students registered in the course of methods and styles of education in the physical education and the course of sport psychology and their number is (101) students (males and females) from both Universities. Results resulted in the existence of statistical differences in trends of students for the interest of students of the University of Jordan on three dimensions of the scale four dimensions and on the scale with its complete from. Meanwhile, statistical differences appeared between male students and female students for the interest of females. And also statistical differences appeared for the interest of students with more experience in computer and students with the high attainment.

(8) Songkhala (1988) did a comparative study to reconnoiter students' trends and teaching staffs about using of the educational Internet at four universities in the Tyland capital. Results showed that individuals of the sample did not use the Internet a great deal for communication purposes, and students are not at a high degree of skill in using the net and communicate through, and the individuals of the sample did not consider the net an educational means of communication.

(9) Padfield and Pennington (2000) had laid a study aiming at reconnoitering trends of students towards using the computer skills (programs) in teaching skills of the Volley-ball in the physical education. The results showed that there are positive trends towards this type of education, and the two researchers recommended to use the computer skills in teaching the physical education skills.

(10) Al-A'alaowneh (2002) had organized a study in Jordan aimed at investigating the effect of education by the computer in acquiring skills of innovative thinking in the engineering design at a sample consisted of (60) students (males and females) from the Seventh Basic Grade, distributed between two groups, one of them is disincentive, its size amounted to (30) students, studied by the classical way, and another empirical its size amounted to (30) students, studied by the computer way. The researcher used two instruments in the study, the first: attainment test and the second a computerized program. And results showed existence of differences statistically indicative for the interest of the empirical group.

(11) And Al-Raddadi (2008) prepared a study aimed at investigating the effect of computerized educational program depending on solving problems in attainment and developing the innovative thinking in the science subject for students of the second Medium Grade in Medinah, scholastic year 2006/2007 whose number amounting to (10658). And the sample of study consisted of (50) students, were divided into two groups: a disincentive group consisted of (25) students, studied the science subject by the habitual way, and an empirical group consisted of (25) students, studied the science subject by the computerized educational program depending on solving problem. And to achieve objectives of study, the researcher designed a computerized educational program, and the researcher used a number of instruments, they are: Torans for innovative Test... vocal from (a), and attainment test for the content of the science subject, and a scale of students trends towards the computerized educational program. The results of study cleared as follows: existence of differences with statistical indication in attainment and innovative thinking within the medium of performance of the empirical and disincentive groups, that is for the interest of the empirical group. And also the results of study assured the excellence of the empirical group in the subsidiary thinking skills as a solution of problems, innovation, evaluation and analysis on their computer parts in the disincentive group.

\section{Population and Sample of Study}

The community of study consisted of all students of the bachelor degree in the College of Basic Science in The World Islamic Sciences and Education University (WISE), their number amounted to (200) students (males and females), and the sample of study consisted of (140) students (65 male students and 75 female students), they were selected by the purposeful method from students of the College of Basic Science in the World Islamic Sciences and Education University, in the first semester (2012/2013).

\section{Procedures of Study}

Questionnaire of trends towards using the computer as an assisting means in the education operation:

After checking plenty of researches and previous studies related to trends of students towards using the computer as an assisting means of education in the educational operation, the questionnaire prepared by Al-Hayek (2004) 
was selected, that was because of its appropriateness and nature of this study and its objectives. For Al-Hayek implemented this questionnaire on students of the Faculty of Physical Education in the University of Jordan, and founded its validity by showing it to (ten) of referees holding the degree of doctorate in physical education and educational Sciences in both universities; the Yarmouk and the University of Jordan, to give their point of view about appropriateness of paragraphs with dimensions of scale, and the extent of their comprehensiveness in measuring trends of students towards using computer, and also suggesting what they see suitable of paragraphs and new concepts. Suitable amendments were done, and included the questionnaire in its final form (32) paragraphs. Also Al-Hayek (2004) founded steadiness of the questionnaire by Test-Retest on a sample consisted of (20) students (males and females) not from individuals of study. Then repeated implementing the test once again on the same sample after ten days from the first implementation and under the previous circumstances and conditions, and a connection coefficient was founded between degrees of the scales in both implementations, and was (\%84). It is a high degree of steadiness approximately, that indicates the questionnaire is firm. And the steps of ladder of response were distributed from (1-5) steps in accordance with (Likert) five old scale as follows:

(1) To answer I extremely disagree.

(2) To answer I disagree.

(3) To answer neutral.

(4) To answer I agree.

(5) To answer I extremely agree.

And therefore the whole degree of the scale amounts between (32) at the lowest limit and (160) degrees at the highest limit. Paragraphs of the questionnaire were distributed on the following four dimensions:

The first dimension: the scientific and cognitive dimension to use the computer.

The second dimension: after accepting the computerized educational subject.

The third dimension: the dimension of the role of the computer as an instructor.

The fourth dimension: the psychological dimension to use the computer.

And it is obliged to be mentioned that the questionnaire includes information and general questions too concern sex.

\subsection{Designing of Study and Statistical Treatment}

This study included the following variables:

a. Independents variable: sex has two levels the first males and the second females.

b. Following variable: trends of students towards using the computer in educating the subjects of athletics and health at the College of Basic Science.

\subsection{Statistical Treatments}

(1) Arithmetic means (A.M).

(2) Standard deviation (S.D).

(3) (SPSS) program was used to analyze and statistically treat data.

\section{Results and Discussion}

The statistical analysis of data showed in light of sex variable at students of the College of Basic Science in the World Islamic Sciences and Education University the sample of study about the following results (classified in accordance with the questions of study:

The first question: What is the degree of students' trends in the College of Basic Science towards educating the course of athletics and health by using the technology of computer in the World Islamic Sciences and Education University?

It appears from the table that the degree of students trends on the first dimension, the scientific and cognitive dimension to using computer was high in general; the arithmetic mean amounted to (3.82), and standard deviation (0.52), and paragraph (1) came in the first position, it is: "computer develops my ability on scientific thinking" with arithmetic mean (4.36) and standard deviation (0.65) with high degree of trend, and the last position, paragraph(8) "learning by the computer makes me more incentive to learn more of athletic cognition", with an arithmetic mean (3.39) and standard deviation (0.79) and with a medium degree of implementation. 
It appears from Table 2 that the degree of students' trends on the first dimension after accepting the computerized educational subject was high in general, for the arithmetic mean amounted to (3.82), and a standard deviation of (0.52), and paragraph (9) came in the first position, it is: "I support generalization of learning by the computer to all educational subjects in physical education" at an arithmetic mean of (3.97) and a standard deviation of (1.06) and at a high degree trend, and at the last position was paragraph (16) "Learning by computer assists in learning abundant information in a short time" at an arithmetic mean of (3.46) and a standard deviation of (0.79) and at a medium implementation degree.

The degree of students' trends appear from Table 3 that third dimension, dimension of the computer role as instructor was high in general for arithmetic mean amounted to (3.82), with standard deviation of (0.52), and paragraph (17) came in the first position. It is: "learn by computer at a better way than by instructor". By an arithmetic mean of (4.31) and a standard deviation of (0.65) and at a high degree of trend, and in the last position, was paragraph (24): "Learning by computer is done hastely", by an arithmetic mean of (3.51) and a standard deviation of (0.83) and at a medium implementation degree.

Appears from Table 4 that the degree of students' trends on the fourth dimension, the psychological dimension of using the computer was high in general, for the arithmetic mean amounted to (3.82) and with standard deviation of (0.52), and paragraph (25) came in the first position it is: "I feel with ease when I am entrusted with any job related to the computer" arithmetic mean (3.68) and standard deviation (0.94) and a degree of high trend, and in the last position paragraph (32) was: "I do not feel boring when using the computer" with an arithmetic mean of (3.68) and standard deviation of (0.94) and a degree of medium implementation.

The second question: are there differences with statistical indication at the level of $(0.05<\alpha)$ in students trends towards using the computer in educating the subject of athletics and health in the College of Basic Science ascribed to sex variable?

To examine this question the arithmetic mean and the standard deviation and the value of $(\mathrm{T})$ were counted to compare between male students responses and the means female students responses on each dimension of scale dimensions and the scale as whole, which Table 5 shows. For Table 5 pin-points non-existence of differences with statistical indication between trends of male students and female students towards using the computer technology in learning the subject of athletics and health on all scale dimensions factor in distinguishing the trend towards using technology of the computer in educating the subject of athletics and health, that is male students do not differ in their trends towards using technology of the computer in learning the theoretical subjects about trends of female students.

This result can be ascribed to that both sexes are exposed to the same scientific and practical experience in the college, and they also study the same subjects by the same methods and styles of education approximately, and so they are exposed to the same academic experience. And this result agrees with what Al-Hayek (2004), Ahmad (2000), Al-O'mari (1997), Al-A'abdllah (1991), Al-Aa'li (1996), and Malak (1995) deduced, and also differs with what Al-Hayek and Suha (2006), Abu-Jaber and Abu-O'mar (2000), Abu-Shararah (1996), Shashani (1995), Abu-Jaber and Al-Badaineh (1993), and Voogat (1987).

In light of the former narration it can be said that there are positive trends at the students, sample of study towards using the computer technology as an assistant means in educating the subject of athletics and health. And these results may be ascribed to the following reasons too:

- Variety of ways of showing information to the learner the thing that drives feeling with anxiety away.

- Accessibility of getting information from all over the world, and checking views and points of view of scholars researchers and specialized figures in different fields.

- Organizing both operations of thinking and learning at the learner, and submersion of learner actually in the educational operation, that made him positive and active towards learning.

- Presenting arousing desire and various educational programs, which suit propensities and needs of learners from one part and observing the individual differences among them from the other part, that makes them more incentive and motive to learning.

- The student feels that he is escorting the technical technological progress.

- Supporting opportunities of self-learning.

\section{Deductions}

In light of objectives and results of study we can deduce the following: 
- There are positive trends towards educating the subject of athletics and health by using technology of the computer as an assistant educating means at the College of Basic Science in the World Islamic Sciences and Education University.

- There are no differences with statistical indication between male students and female students towards using technology of the computer as an assistant education means.

\section{Recommendations}

- Doing more researches in the field of students' trends at all universities, which endeavor to educate the course of sports and health, or sports in our life.

- Assuring on the course of sports and health to be an obligatory requirement for all university students.

- Necessity of using the computer and the Internet in educating the course of sports and health at the universities of Jordan as an educational means to escort the scientific and technological development.

\section{References}

Abu-Jaber, M. A. (2000) Students and instructors' trends towards the computer at schools of Governments of South Jordan. Dirasat, 27(2), 364-381.

Abu-Jaber, M., \& Al-Badaineh, B. (1989). Students' trends towards using the computer. Message of the Arab Gulf, 13(46), 123, 162.

Abu-Shararah, T. (1996). Effect of the study of the subject of computer in students' trends towards using the computer, due to difference of sex and previous experience (Unpublished master degree dissertation). University of Jordan, Amman, Jordan.

Al-Alaowneh, M. (2002). Effect of Teaching by assistance of the computer in acquiring skills of geometry-drawing at students of the Ninth Basic Grade compared to the classical methods (Unpublished master degree dissertation). Al-Al-Bait University, Mafraq, Jordan.

Al-Hayek, S. (2004). Effect of using computer as an assistant educating means on trends of students of the Faculty of Physical Education towards the computer.

Al-Hayek, S., \& Salameh, B. (2006). Effect of learning Swimming by using the Internet on the skillful performance level at students. Conference of the Faculty of Physical Education in Alexandria University, Egypt.

Al-Hayek, S., \& Suha, I. (2006). Effectiveness of using computer in educating methods of the Faculty of Physical Education on Students' trends towards it in the University of Jordan and the Hashemite University.

Al-Jabiri, N. M. (1993). Students of the first Secondary Class trends towards the subject of the computer in the state of the United Arab Emirates (Unpublished master degree dissertation). University of Jordan, Amman, Jordan.

Al-Mahameed, S. (2007). Effect of Computerizing Selected Sport Movement Skills on Trends of Students of Ninth Basic Grade towards using the computer in educating the subject of physical Education (Unpublished master degree dissertation). Faculty of Educational Sciences, University of Jordan.

Al-Raddadi, B. A. (2007). Effect of Computerized Educational Program Depending on Solving Problems in Attainment and Development of Innovative Thinking (Unpublished master degree dissertation). University of Jordan, Amman, Jordan.

Al-Shawwa, H., \& Al-Hayek, S. (2006). Effect of Teaching by using the computer on the level of Anxiety at students.

Malak, H. A. (1995). Effect of using the method of learning by the computer (Unpublished master degree dissertation). Yarmouk University, Jordan.

Mohnsen, B. (2001). Using Instructional Software to Meet National Physical Education Standards. Journal of $\begin{array}{llll}\text { Physical Education, Recreation and } & \text { 19-22. }\end{array}$ http://dx.doi.org/10.1080/07303084.2001.10605846

Padfield, G., \& Pennington, T. R. (2000). Student perception of using skills software in physical education. Journal of Physical Education, Recreation and Dance, 71(6), 37-40, 53. http://dx.doi.org/10.1080/07303084.2000.10605160 
Subh, Y., \& Ajlouni, K. (2003). Effect of using the computer in Teaching Mathematics for students of the First Secondary Scientific Class on their Attainment and trends towards the computer. Dirasat Journal, University of Jordan, Amman.

Voogat, J. (1987). Computer Literacy in Secondary Education: The Performance and Engagement of Girls. Computer and Education, 11(4), 305-312. http://dx.doi.org/10.1016/0360-1315(87)90032-7

\section{Copyrights}

Copyright for this article is retained by the author(s), with first publication rights granted to the journal.

This is an open-access article distributed under the terms and conditions of the Creative Commons Attribution license (http://creativecommons.org/licenses/by/3.0/). 